count to return to an acceptable value, usually within a fortnight. In the first two years since the drug's introduction 2337 patients have received clozapine in Britain. Seventy four of the patients $(3 \cdot 2 \%)$ have developed neutropenia induced by clozapine. Of these 74 patients, 11 developed agranulocytosis, of whom one died-a patient who had received clozapine for eight weeks.

Although neutropenia is the most important side effect of clozapine, other clinically important side effects occur in over half of patients. These include sedation in up to one fifth of patients; hypersalivation, which can be severe in up to one fifth of cases; considerable weight gain; electroencephalographic changes in up to a quarter of patients; electrocardiographic changes; and seizures in one in seven patients treated with more than $600 \mathrm{mg}$ a day. ${ }^{310}$

The need for regular blood sampling and the drug's side effects probably account in part for the considerable lack of compliance with treatment. (In our experience the rate of non-compliance is between $30 \%$ and $50 \%$.) Careful selection of patients for treatment is therefore important.

Partly because of the expense of regularly monitoring blood samples, treatment with clozapine costs about $£ 2000$ a year in Britain, which is much higher than for typical antipsychotic drugs. Indeed, this figure may be an underestimate owing to the hidden costs of the time taken for blood tests and to supervise treatment." A cost-benefit analysis has shown, however, that for patients with schizophrenia resistant to treatment clozapine would lead to a net gain of 5.87 years of life with no disability or only mild disability and that the direct costs of using clozapine are $£ 91$ less per year than for standard treatment with typical antipsychotic agents when the effects on all health care resources are taken into account. ${ }^{12}$
Thus the cost of treatment with clozapine is similar to that of other neuroleptics. ${ }^{13}$

A new generation of neuroleptic drugs is being modelled on the pharmacological profile of clozapine-that is, stronger central serotonin $S_{2}$ activity and weaker dopamine $D_{2}$ activity than with typical neuroleptics. It is too soon to report on their efficacy in refractory patients.

STEVEN R HIRSCH Professor of psychiatry

BASANT K PURI

Department of Psychiatry, Honorary lecturer

Charing Cross and Westminster Medical School,

London W6 8RP

1 McKenna PJ, Bailey PE. The strange story of clozapine. Br $\mathcal{f}$ Psychiatry 1993;162:32-7.

2 Kane J, Honigfeld G, Singer J, Meltzer H. Clozapine for the treatment-resistant schizophrenic: a double-blind comparison with chlorpromazine. Arch Gen Psychiatry 1988;45:789-96.

3 Naber D, Hippius H. Drug treatment of schizophrenia: current concepts. Atypical antipsychotics: clinical advantages. Kyoto: Sandoz, 1990:3-4. (Symposium abstracts.).

4 Lindstrom LH. The effect of long-term treatment with clozapine in schizophrenia: a retrospective study in 96 patients treated with clozapine for up to 13 years. Acta Psychiatr Scand 1988;77:524-9.

5 Meltzer HY, Burnett S, Bastani B, Ramirez LF. Effects of six months of clozapine treatment on the quality of life of chronic schizophrenic patients. Hospital and Community Psychiatry 1990;41: $892-7$.

6 Meltzer HY, Gudelsky GA. Dopaminergic and serotonergic effects of clozapine: implications for a unique profile. Arzneimittelforschung 1992;42:268-72.

Pickar D, Owen RR, Litman RE, Konicki E, Gutierrez R, Rapaport MH. Clinical and biologic response to clozapine in patients with schizophrenia: crossover comparison with fluphenazine. Arch Gen Psychiatry 1992;49:345-53.

8 Fitton A, Heel RC. Clozapine: a review of its pharmacological properties, and therapeutic use in schizophrenia. Drugs 1990;40:722-47.

9 Melzzer HY. Clinical studies on the mechanism of action of clozapine: the dopamine-serotonin hypothesis of schizophrenia. Psychopharmacology 1989;99(suppl):S18-27.

10 Alphs LD, Meltzer HY, Bastani B, Ramirez LF. Side effects of clozapine and their management. Atypical antipsychotics: clinical advantages. Kyoto: Sandoz, 1990:7-8. (Symposium abstracts.) 11 Healy D. Psychopharmacology and the ethics of resource allocation. Br f Psychiatry 1993;162:23-9. 12 Davies LM, Drummond MF. Assessment of costs and benefits of drug therapy for treatmentresistant schizophrenia in the United Kingdom. Br f Psychiatry 1993;162:38-42.

13 Bosanquet N, Zajdler A. Psychopharmacology and the ethics of resource allocation. Br $\mathcal{F}$ Psychiatry 1993;162:29-32.

\title{
What does London need from its ambulance service?
}

\section{More thought about how best to improve clinical care}

Last November South West Thames Regional Health Authority set up an inquiry into the failure of the London Ambulance Service's computer aided dispatch system and its wider implications for the management of the service. ${ }^{1}$ Although the inquiry team's report criticised the pace and manner in which the untested system was implemented, the team was convinced that the service should continue to move towards the orderly introduction of a computer aided dispatch system. ${ }^{2}$ Two months ago the London Ambulance Service's management board was dissolved and replaced by a more directly accountable arrangement. ${ }^{3}$

When a 999 call is made to the London Ambulance Service the public has a right to expect a quick response to the call and the quick dispatch of an ambulance. The service, however, deals with 500000 such calls each year, and under current quality standards ${ }^{4}$ no allowance is made for the urgency of the call. Two of the key blanket standards are that $95 \%$ of calls should have a response activated within three minutes and that in $95 \%$ of cases an ambulance should arrive within 14 minutes. In March the performance figures for the service were $47 \%$ and $67 \%$ respectively (London Ambulance Service, personal communication).

If we accept that some calls require a faster response than others then we must question these blanket standards. But how do we ensure that the best response is provided effectively and economically? Several possibilities exist.

Firstly, the London Ambulance Service must attempt to limit the number of calls placed on its resources. Although few data have been collected in London, studies in Chester and Birmingham suggest that up to a half of emergency calls are medically unwarranted. ${ }^{56}$ As the largest emergency ambulance service in Britain, London's service would be ideally placed, with help from central government, to organise and evaluate a campaign to educate the public about the right use of the emergency service.

Secondly, the service should continue to move toward the design and implementation of a computer aided dispatch system that allows the response to be matched to the medical need. Computer technology should greatly enhance this process. After the caller has been reassured that help is on the way, an opportunity exists to provide first aid instructions over the telephone. ${ }^{7}$ These elements form the basis of a medical priority dispatch system, which differs from criteria based dispatch systems by using algorithms rather than prompts. Such systems have been used for 15 years in metropolitan areas in the United States ${ }^{8}$ and have the benefits of being more structured, requiring little training, being easy to audit, and minimising the stress to the controller. A key function of the system is to prioritise the allocation of ambulance resources to 999 calls for which the response time is crucial to the patient's survival.

The current strategy of the Department of Health is that there should be at least one trained paramedic in every emergency ambulance crew by the end of $1995 .{ }^{\circ}$ Currently, 
about one quarter of ambulance crews in London are paramedics, but analysis of workload suggests that less than one tenth of calls require paramedical skills. The London Ambulance Service already trains more paramedics than any other service in Britain and loses some of them to provincial services after training.

Only one third of hospitals served by the London Ambulance Service provide clinical training placements for paramedics, and even to meet current needs this will require a substantial increase. To achieve the Department of Health's target will require a substantial increase in training at considerable cost. Is this likely to be economic? How will most paramedics maintain their skills when only a small proportion of calls require them $?^{10}$ Will the damage to the morale of staff who are not paramedics, seen in other services with the development of an elite; occur in London? The London Ambulance Service has avoided many of these problems by ensuring that some extended skills, such as provision of defibrillation and nebuliser treatment, are taught to every qualified ambulance person. Evidence also exists that ambulance staff who are not paramedics can safely identify and treat hypoglycaemia with glucagon. ${ }^{11}$ If implementing a dispatch system responsive to medical priority shows that resources are being effectively targeted according to clinical need the aim of having a paramedic in every front line vehicle would need to be reconsidered.

Historically, informal links with individual clinicians and specialty groups have facilitated many changes in ambulance training, operations, and equipment. As the range and complexity of prehospital care increases, however, the mechanisms for medical input to the London Ambulance Service and the audit of outcomes will need review. Currently, there is official medical input to extended training in the form of the paramedic steering committee as required by the NHS Training Directorate, but in other matters of policy the only other medical forum, the medical advisory group, has no operational responsibilities. Recent initiatives that have required close liaison are the development of joint training for ambulance and medical incident officers in the management of major incidents, ${ }^{12}$ proposals for increasing direct communication between ambulances and accident and emergency departments, and the development of alternatives to obstetric flying squads. ${ }^{13}$ The input of the medical advisory group to long term planning and development would be valuable.

Unified medical input and systematic audit ${ }^{14}$ are particularly necessary in view of the differing medical opinions and prejudices regarding the philosophies of "scoop and run" versus "treat in the street." How best to coordinate medical advice for the London Ambulance Service should be a matter for debate. In particular, the potential benefit to London of the consultant medical director model-popular in the United States and currently being pioneered in the Scottish Ambulance Service-will need careful assessment.

Public interest in the London Ambulance Service is obvious, but public confidence, shaken by the 1989 ambulance strike and by the problems of last year, needs to be restored. Although response times have the highest profile-being easily measured - the quality of clinical care delivered is also crucially important, and its absence from the topics included in the service's annual corporate review is regrettable. ${ }^{15}$

The London Ambulance Service's new management must make an unequivocal commitment to both basic and extended training and the establishment of systematic clinical audit to build on the progress made to date. As a consumer, the public has a part to play in making the service more efficient, and a health education campaign supported by the government is long overdue. Management commitment is likely to produce better response times over the next three years, but this will be a hollow achievement without advances in clinical care.

ROBERT A COCKS

Hammersmith Hospital, London W12 0HS

Consultant in accident and emergency

King's College Hospital,

EDWARD GLUCKSMAN

London SE5 9RS

Consultant in accident and emergency

Warden J. London's ambulance service fails. BMF 1992;305:1116.

South West Thames Regional Health Authority. Report of the inquiry into the London ambulance service. London: Communications Directorate, SWT RHA. 1993.

service. London: Communications Directorate, SWT RHA. 1993
London ambulance service board scrapped. $B M 7$ 1993;306:950.

3 London ambulance service board scrapped. BMF 1993;306:950.

Gardner GJ. The use and abuse of the emergency ambulance service: some of the factors affectin the decision whether to call an emergency ambulance. Arch Emerg Med 1990;7:81-9.

6 Morris DL, Cross AB. Is the emergency ambulance service abused? BMF 1980;281:121-3.

Clawson J, Hauert S, Martin RL. Advanced EMD course manual. Salt Lake City: Medical Priority Consultants, 1992.

8 Kellerman AL, Hackman BB, Somes G. Dispatch-assisted cardiopulmonary resuscitationvalidation of efficacy. Circulation 1989;80:1231-9.

9 Department of Health. The health of the nation: key area handbook: accidents. London: DoH, 1993.

10 Walters G, Glucksman E. Retention of skills by advanced trained ambulance staff: implications for monitoring and retraining. BMf 1989:298:649-50.

1 Steel JM, Allwinkle J, Moffat R, Carrington DJ. Use of Lucozade and glucagon by ambulance staff for treating hypoglycaemia. $B M 7$ 1992:304:1283-4.

2 Cocks R. On site medical services at major incidents. BMF 1992;305:1015.

13 Royal College of Obstetricians and Gynaecologists. The future of emergency domiciliary obstetric services ("flying squads"). London: RCOG, 1990.

14 Polsky SS, Weigand JV. Quality assurance in emergency medical service systems. Emerg Med Clin North Am 1990;8:75-84.

15 South West Thames Regional Health Authority. Revised accountability arrangements for the London Ambulance Service. London: Communications Directorate, SWTRHA, 1993.

\section{Measuring patients' views: the optimum outcome measure}

\section{SF 36: a valid, reliable assessment of health from the patient's point of view}

The debate about whether and how to measure medical outcomes is heating up as those who fund medical care put providers under greater pressure to control their costs. With little known about which features of medical services improve outcomes, policies that reduce costs will be deemed successful unless data on outcomes show otherwise. Hence the need to study outcomes.

The ideal outcome of treatment is a return to the normal or usual quality of life for a given age and medical condition.' Since the first health interview surveys of sickness and disability, the hunt has been on for a reliable measure of how people perceive their health. ${ }^{2}$ Great strides have recently been made in standardising self reported measures of functioning and wellbeing and using them to monitor outcomes. With the standardised self report survey emerging as the best method of measuring outcomes from the patient's point of view, now is a good time to take stock of these advances.

- To date the evaluation of such surveys has mainly been controlled by the researchers who developed them, but health care policy makers, clinical investigators, and providers should now get involved. The contributions of Jenkinson and colleagues ( $p$ 1437) 3 and Garratt and colleagues ( $p$ 1440) ${ }^{4}$ in this week's journal and an earlier contribution by Brazier et $a{ }^{5}$ provide useful information about the performance of the 